\title{
Marketplace metaphors: communicating authenticity through visual imagery
}

\author{
by \\ Paul Freathy* \\ and \\ Iris Thomas
}

Institute for Retail Studies

Stirling Management School

University of Stirling

Stirling

Scotland

FK9 4LA

j.p.freathy@stir.ac.uk

*Contact Author 


\title{
Marketplace Metaphors: communicating Authenticity through visual imagery
}

\begin{abstract}
While the concept of authenticity is commonly linked to the market exchange process, it also assists in the pursuit of political, social and economic objectives. Authenticity provides a legitimating function that serves the needs of specific groups and individuals. Establishing authenticity remains culturally and contextually dependent and requires an understanding of prevailing power relationships and historical events. This is demonstrated by reference to a series of sixteenth and seventeenth century images of retailing and the marketplace. Using iconological interpretive techniques, the paper identifies how works of art served a propagandist role designed to influence and modify public opinion. Developments in both production and consumption led to a commodification of artistic works and afforded a means of communication that both challenged and empowered established institutions. The paper highlights the contemporary significance of these findings and suggests that modern marketing imagery may seek to authenticate socio-political as well as economic meaning.
\end{abstract}

\section{Keywords}

Authenticity

Iconology

Art

Retail

Genre painting

Symbolism 


\section{Introduction}

The concept of authenticity remains a central feature within marketing and consumption scholarship (Beverland et al. 2008; Grayson and Martnec 2004; Trilling 1972). Despite vagaries in its definition and a lack of objectivity in its characterisation, it is recognised that 'the authentic' can provide both commercial and market related benefits (Newman and Bloom 2012). Often associated with a previous / bygone era, attention has focused upon linking a product or event with its historical past (Firat and Ulusoy 2011; Hede and Thyne 2010; Rose and Wood 2005; Peñaloza 2001). For consumers, authenticity can provide a representation of what is, what has been or even what should have been and, despite its inherent subjectivity, can serve to both legitimise actions as well as reinforce beliefs.

While a number of studies have identified the commercial and economic benefits that may result from establishing a products authenticity, focus has often been placed upon understanding its current marketing relevance (Beverland 2005; Beverland et al. 2008; Brown et al. 2003; Peñaloza 2001). Authenticity however is not a contemporary reaction to modernity (Trilling 1972) and remains historically as well as culturally embedded within consumer society. Despite this, there have been only limited attempts to understand how authenticity was established and maintained during different periods of history. This paper aims to partially address this gap by examining how authenticity was employed in the fifteenth and sixteenth centuries and used in the pursuit of economic, social and political objectives.

The Renaissance era (circa 1400 - 1600) represents a period of significant cultural transformation and social enlightenment (Hall 1994). Intellectual reform was complemented by scientific advancement and literary emancipation. The visual arts similarly evolved with a movement away from the "contemplative abstract form" (Schroeder and Borgerson 2002, 
156) towards more human and natural representations. The new freedoms that characterised much of the Renaissance period were accompanied by changes in both the production and consumption of artistic works. For example, in Italy, economic developments saw the emergence of the merchant classes and an increase in wealth and materialism. The ownership of works of art became an indicator of affluence and prestige as well as a means of communicating image, style and propaganda.

Paintings represented an established form of communication and, while the popularity of print was beginning to grow, the overwhelming majority of individuals in Europe remained uneducated and illiterate (McTighe 2004). Paintings, sketches, frescos and drawings represented a primary means of communicating with the populace and as Brown et al. (2003) maintain, such original works of art exuded authenticity. The interpretation of these culturally contextualised narratives would in turn, be dependent upon audiences being able to understand the imagery they encountered (McTighe 2004; Pracejus et al. 2013; Schroeder 1999; 2005). Many Renaissance works however sought to move beyond the aesthetic to provide broader socio-economic and political commentary as well as communicate more specific agendas. Understanding the context within which works of art are produced and being able to interpret the meaning contained within visual imagery, provides a rich and important source of cultural data that offers a historical insight into changing consumer tastes, trends and values.

To achieve its aim, the paper first details the concept of authenticity and its role in communicating and legitimising meaning. The techniques used to interpret visual artworks from the Renaissance period are then outlined before iconological analysis is used as an interpretative framework. These conceptual sections are followed by a brief discussion of why the late sixteenth and early seventeenth centuries were considered suitable for study. A 
series of artistic works are then examined before the paper's contribution to consumption, markets and culture is considered.

\section{Establishing Authenticity}

While studies surrounding the inherent value of the 'real' and the 'genuine' are often associated with consumer marketing scholarship, authenticity has previously been explored in a number of different academic fields including sociology, geography, anthropology, tourism and literary criticism (Derbaix and Decrop 2007; MacCannell 1973;1976; Shepherd 2003). Authenticity has also been linked with the concept of nostalgia as both seek to explore how consumer values and contemporary patterns of consumption have been influenced through memories of the past (Higson 2014). Indeed, some such as Potter $(2010,270)$ have viewed authenticity as "a dopey nostalgia for a non-existent past". Despite this, numerous studies have sought to define the purpose of authenticity (Beverland and Farrelly 2010; Beverland et al. 2008; Grayson and Martinec 2004; Holt 2004), understand how consumers differentiate between the authentic and inauthentic (Barrere and Santagata 1999) as well as identify the criteria upon which individuals seek to assign authenticity (Beverland et al. 2008; Zayer et al. 2012).

This paper explores the different motivations of those who actually seek to create or deliver the authentic (or inauthentic). For example, Chronis et al. (2012) argue that authenticity cannot be disassociated from notions of power and commercial interest. Similarly, Beverland (2005) demonstrated how by making links to historical and cultural referents and by committing to values above commercial consideration, firms were able to establish their authenticity and consequently increase their market equity. While supporting this view, this paper will argue that in addition to economic motivations, authenticity is 
inextricably linked to the achievement of other, political and social goals. While one may agree with Beverland $(2005,1005)$ that "the persistence of authenticity ... lies in the legitimacy of established institutions" it also remains valid to suggest that the persistence of institutions lies in the establishment of their own authenticity.

A suggestion of what is authentic may involve selectively appropriating views of the past through specific literary and visual cues. As Wang (1999) notes, history is not objective and may be constructed to reflect specific beliefs, ideologies and interests. For example, it is argued that nation states develop an official memory that is created by those who seek social unity, loyalty and the continuity of particular institutions. Past events are therefore continually reconstructed in the context of the present (Osborne 1998). The celebration of historically significant dates, people and locations seeks to authenticate and legitimise the actions of the state by exemplifying past deeds and achievements. Far from providing objective, disengaged portrayals of previous events, both literary narratives and visual imagery consistently serve to reinforce particular versions of history.

Consumer's understanding of past events may therefore revolve around mythical, romantic or sanitised versions of history with media and communications playing a critical role in creating the authentic (Peñaloza 2001). Such representations may act as expressions of self-interest that serve the economic, social or the political needs of dominant groups or individuals. In this context, authenticity serves as a form of legitimisation that remains linked to the exercise of power. The manipulation of visual, verbal and literary expression is used as a means of establishing normative principles around specific agendas. This is not to suggest that each individual is a passive recipient, submissively reacting to the production of meaning nor is it to imply that persons are necessarily the unwilling victims of 'sinister powers' being surreptitiously mislead into believing that they are enjoying an authentic experience (Cohen 
1998, 373). Rather, consumers are viewed as co-creators of meaning who may be actively involved in the construction of authenticity.

Those who succeed in creating an 'acceptable authenticity' may (for a period of time) have the power to render alternative or previous perspectives as inauthentic and limit the interests of those with counter views (Edwards 2010). However, maintaining the normative view requires the consistent working and reworking of the authenticating mechanisms (Beverland 2005). Changing events, interests and multiple information sources continually challenge the legitimisation process and require continued negotiation amongst market players (Peterson 1997).

\section{Art, authenticity and iconography}

While authenticity is often established through linkages with the past, for some commentators the creation of the authentic is not asserted by any reference to previous events, to places or historical objects. Beverland et al. (2008) describes a form of 'moral authenticity' which is derived from the creative act itself. The intent of the craftsman, the skills, commitment and judgement employed, all play a central role in assigning authenticity and, while this may reinforce the legitimacy of the message, visual imagery has also long been able to merge the actual with the imaginary (Hartmann and Ostberg 2012; Fine 2006; Torikian 2010).

Works of art therefore do not necessarily seek to represent a "real" world. Perceptions of reality are gained through ones exposure to the narratives that surround the image. Political actions, social relationships as well as views on science and nature can be guided, constructed and periodically reconstructed through visual imagery (Biehl-Missal 2013; Edelman 1995). Artistic works may not only seek to provide legitimacy, they may create multiple and diverse levels of meaning. Although discourses on the existent and the illusionary nature of art are more commonly associated with contemporary post-modern theory (Higson 2014), the 
inclusion of signs and symbols within historical works has similarly served to convey meaning, shape opinion and influence behaviour (Bedaux 1978; Panofsky 1970; Gombrich 1985). The concept of Iconology has parallels with the semiotic interpretation of literary texts and the more contemporary analysis of advertising imagery (Schroeder 2006). Interpretation remains context dependent and cannot easily exist without reference to the cultural, political and social environments that surround their production and consumption (Harrison 2009; Schroeder and Borgerson 2002).

The personal nature of the iconological approach places obvious constraints upon this form of investigation and is recognised as being intuitive, unscientific and reliant upon the subjective interpretation of those who seek to look for deeper meaning (Gombrich 1985; Panofsky 1970; 1971). Hirsch (1967) recognised this limitation and maintained (simply) that a work of art means what the artist intended it to mean, it is the role of the interpreter to establish what this actually was. The explicit use of conventional codes, signs and literary keys does not unequivocally assign meaning to a painting or establish the legitimacy of the message. The implicit nature of iconology means that it is not something derived from agreement, individuals interpret the cues provided by the artist and provide differing assessments on what comprises the authentic (Maruyama et al. 2008).

Multiple interpretations of the same work and an over-interpretation of the text remains possible as each symbol can exhibit a 'plentitude of meanings' (Gombrich, 1985, 14). As a consequence, there exists a danger of simply identifying individual signs and symbols within a work and assigning meaning based upon the recognition of various images. To assist interpretation therefore, meaningful analysis may be aided by historical and cultural contextualisation that draws upon artistic conventions and locates a work within a particular genre (Bedaux 1987; Hirsch 1967; Schroeder 1999). 


\section{Genre Paintings and the portrayal of the 'real'}

Welch (2005) maintains that until the late 16th century depictions of commercial activity were confined (in Europe at least) to either frescos or footnotes in manuscripts and carried little iconographic meaning. This mirrors McKiernan's (2008) more general observation that prior to the Renaissance period, 'work' as a theme had traditionally been ignored by the artistic establishment who deemed it unsuitable for intellectual attention. However from the 1550 's onwards, a growing interest was witnessed in 'low life' subject matter and the use of iconic visual references to illustrate scenes of everyday life.

Particularly popular in Italy, the Netherlands and England, genre paintings sought to provide a snapshot of life through a vast array of subject matter from street scenes and markets to bars and taverns (Stern and Schroeder 1994). The emergence of this tradition was not only a form of post-Reformation religious iconoclasm, but also a reaction to the growing demand for artistic works amongst the emerging merchant classes. During the Renaissance period, paintings became collectable commodities that not only signalled wealth and status but also provided the means to communicate stability and reassurance (Brown 1999). Parts of Europe in the sixteenth century had been characterised by significant economic, political and cultural change and paintings that depicted views of daily life served as reminders of an earlier, simpler existence. As Brown et al. $(2003,29)$ note, the appeal of an idealised past (Arcadia) had great attraction as it represented "an imagined era of moral certainty".

Many paintings would (on the surface at least), seek to depict the culture and life of working class individuals with a degree of "ruthless realism" (Falkenburg, 1996, 13). However if one moved beyond the initial superficiality of the picture itself, the contemporary accuracy of many works was limited (Frantis 2004). For example, the clothing being worn by individuals, the foods being consumed and the activities being undertaken were often 
drawn from periods other than that being depicted. Whilst purporting to provide representations of everyday life, such works sought to communicate with audiences through culturally constructed cues, signs and symbols (Edelman 1995; Witkowski 1996). This was because even the illiterate and semi literate of the time could understand and interpret the intrinsic meaning contained within works of art (McTighe 2004). The purpose of the genre form therefore extended beyond any decorative / ornamental function and was designed to influence attitudes, behaviour and public opinion. Paintings represented one of the primary means of communicating with the populous and for those who commissioned artistic works, a way of achieving specific consumer orientated needs (Schroeder and Borgerson 2002).

Given the limited access most persons had to alternative sources of information during the Renaissance period, there remained little opportunity for individuals to question the legitimacy of the messages they received.

\section{Methodology}

Studies that have sought to develop a semiological understanding of marketing imagery have often been criticised for their subjectivity and tendency to provide the reader with multiple explanations. The analysis of signs and symbols and the deconstruction of hidden meaning, does not lend itself to methodologies that countenance sequence and order. Interpretation cannot be reduced to a linear, staged process, instead, analysis should be an iterative approach that acknowledges diversity and seeks understanding through multiple routes (Holbrook 1989).

Those methodological approaches that aim to understand and explain the visual form do not simply record and report "art as information". An individual's interaction with an image serves to create additional interpretations and establish further meaning. By seeking to deconstruct the unconscious, iconology accepts the elusive nature of artistic imagery and the 
subjective over the objective. Meaning itself is not static and while multiple studies may provide multiple understandings, additional research can and should provide new insights (Drewel 1988; Witkowski 1996). This is not to suggest that any investigation should be free of convention, enquiry may be guided by a structure that ensures an adherence to the principles of interpretation (Soppelsa 1988). To provide a conceptual framework for this paper, the research draws upon Panofsky's (1970) method of iconological analysis. The strength of this approach is its focus upon interpretation rather than description and its ability to allow latitude in analysis while at the same time preventing digression (Soppelsa 1988).

Genre paintings were chosen for this study as they were amongst the first to be concerned with material life and the nature of human existence (Falkenburg 1995; Schroeder 1999). The portrayal of everyday secular activities in streets, inns, taverns and markets provided the opportunity for allegorical reference and represented a departure from traditional religious compositions. In addition, increases in the production and consumption of artistic works during the late 16th century meant that visual imagery had become more accessible to the wider population and was regarded as a legitimate means of communication.

The retail marketplace in particular represented a subject of particular interest to patrons and audiences alike. This was because retailing was a key economic sector that also acted as a barometer of social and political change (Welch 2005). Major works that depicted the vendor, the merchandise and the market would have attracted considerable public attention and have been the subject of discourse and deliberation. While the choice of any painting remains a highly subjective exercise, the following section seeks to interpret the selected works from two Renaissance artists. 


\section{Depictions of the retail marketplace}

During the European Renaissance (circa 1400 - 1600) economic and political turbulence was accompanied by commercial expansion, an increase in wealth and consumerism and a new found liberalism in the arts and humanities. The changes that took place over this period have been credited with providing the foundations for understanding the development of the modern day, consumer orientated society (Schroeder and Borgerson 2002). Reflecting the growing predilection toward conspicuous materialism, the act of shopping enjoyed a new social status and became an activity not only undertaken by servants and workers but also by more privileged, wealthy individuals (Jardine 1996; Welch 2005). Welch (2005) notes the central role retailing played in maintaining social order at this time. Good governance was predicated upon those in authority being able to provide the populace with sufficient goods and services and any failure to do so was likely to lead to social unrest.

A strong and vibrant retail sector was therefore linked to wealth and abundance and considered essential to the peace and security of many cities. Reflecting its role as the hub of commercial activity, the marketplace in particular has been depicted through a variety of different artistic mediums from woodcuts to etchings and from frescos to easel paintings. Such works attracted significant popular interest and were used to convey meanings that ranged from ethical and scientific instruction to reflections on morality and human behaviour (Welch 2005; Witkowski 1996).

\section{The pitture ridicole and symbols of social hierarchy}

Vincenzo Campi (1536 - 1591) was an Italian artist whose compositions included fruit and poultry sellers, kitchen scenes and the Fishmongers (Figure 1). This latter work was one of a series of five paintings commissioned around 1580 for Hans Fugger, a member of the Augsburg nobility who displayed the work on the walls of his dining room at his country 
house in Schloss Kirchheim. The Fuggers were a highly influential family whose links with Augsburg could be traced back over two centuries. Over this period, their commercial interests had grown from a small weaving business to extensive international activities that included textiles, banking and mining. In addition, the Fuggers provided a number of European states with both significant financial assistance as well as military support (Häberlein 2012). Hans Fugger himself was not only an avid collector of antiques and patron of the arts, he also displayed an interest in understanding the forces that shaped the natural world. Reflecting the growing interest in science that characterised the Renaissance era (Hall 1994), Fugger sought to distinguish himself as a humanist scholar concerned with understanding, collecting and cataloguing items of scientific and cultural importance. He established himself as a patron of both the natural sciences as well as classical scholarship and supported academic enquiry through the acquisition of numerous texts and by significantly expanding the family library.

The growth of the patronage system during the Renaissance period however, was not only driven by a quest for knowledge and a want for learning. It was indicative of a wider societal transformation that reflected changes in both the patterns of production and consumption. The ability to commission and amass artistic collections, meant that individuals rather than the church or the state were afforded the opportunity to communicate with the populace. The Fishmongers may therefore be set against Fugger's interest in the ordering of natural phenomena, the pursuit of scientific discovery as well as the desire to promote specific agendas and satisfy personal needs.

\section{Figure 1 The Fishmongers about here}

While some commentators have interpreted the The Fishmongers as little more than a humorous characterisation of peasants in the genre tradition (Wind 1974), others maintain 
that the painting symbolises the enduring nature of social hierarchy and the division between different classes. This contention is partly based upon the notion that foodstuffs could convey specific messages to 16th century audiences. Sullivan (1999) for example argues that different types of fish, meat and vegetables had a definite communicative function and would not have been included purely for visual effect. Some foods could only be consumed by persons of a higher order and those individuals who worked with their hands (villani) could only digest certain 'lower order' foods. For example, in Figure 1 both adults are shown eating beans. This was considered one of the lowest forms of food and like scallions and turnips was associated with individuals of low intelligence and excessive sexual libido (McTighe 2004; Sullivan 1999). Similarly the cheese, walnuts and dark red wine that they are consuming were all foods traditionally reserved for the poor and those who undertook manual labour. In contrast, fish are considered amongst the most "noble" ${ }^{1}$ of foods, the sturgeon on display was prized for both its flesh as well as its eggs and the painting also shows other luxury items such as eels, carp and lampreys (Falkenburg 1996; Miller 2000). None of the products that are for sale are eaten by the vendors as they could neither afford them (nor according to some commentators - be able to digest them). Indeed as McTighe (2004) notes, the consumption of fish and fowl was considered by some to be 'positively harmful' if eaten by the peasant classes.

Further reinforcing the lowly and immoral position of the vendor, the woman is shown wearing a wooden clog or zoccolo. This was a symbol of easy virtue, a position which was further reinforced by the small jar of coins at her feet. The child in the picture is being held by its mother and has a crayfish attached to its finger on the left hand. Shellfish were seen as being powerful creatures with limited intelligence, a reference to the way in which the labouring classes were perceived. The obvious pain of the child means its contorted face resembles its fathers and serves as a reminder of the enduring nature of social hierarchy. The 
child will be destined to follow in the same manual occupation as its parents and despite a lifetime working in proximity to noble foods, will never escape the class to which it was born.

The Fishmongers therefore represents more than a comic allegory. The composition's imagery communicates with audiences through symbolic cues and implied messages. Moreover, its commission by an individual renowned as a patron of the arts and an advocate of universal knowledge serves to further reinforce its authenticity. Fugger's concern with understanding and ordering natural phenomena helps locate the Fishmongers within the (quasi) legitimacy of the scientific renaissance (Hall 1994) and supports the notion that, within European society, there existed a series of objectively derived, social divisions.

Campi's painting communicates the legitimacy of the prevailing social hierarchy and the authenticity of the existing power structures. Its commission may have been in reaction to the societal transformations that were occurring across Europe during this period. For example, in Northern Italy during the late 16th century, the demand for luxury products had not only increased but had also begun to cross social boundaries (Welch 2005). The purchase of non essential goods and fashion items were no longer the exclusive preserve of the dominant elite and the increased availability of manufactured goods combined with a widespread system of credit, allowed even low paid labourers to spend beyond their immediate means. The rise of this early form of consumerism was considered by some as being potentially harmful as it sought to challenge class boundaries and threaten the existing social order.

The Fishmongers may therefore be interpreted within this historical and cultural context. While some have suggested that Campi sought to depict an inherent biological division between two distinct races (McTighe 2004), such a view ignores the Fuggers own 
humble origins and their rise from rural immigrants through the ranks of the urban bourgeoisie to their status as landed nobility. Moreover, official histories from the 16th century do not seek to hide this progression and fully acknowledge the family's background in weaving and textiles (Häberlein 2012). However, while the Fuggers may have accepted the notion of social mobility, any movement was expected to be a gradual process that needed to occur over many generations. The status that the family were accorded during the late 16th century was a reflection of the intellectual and cultural legitimacy that had been gained over the preceding 200 years. By suggesting that those who laboured with their hands (such as retailers) were part of a lower order, the painting does not attempt to deny social mobility, rather it provides a commentary on the dangers of crossing class boundaries without the accompanying, economic, social and political proficiencies.

\section{The market as a symbol of political order and stability}

Welch (2005) maintains that from as early as the 13th Century, Italian writers used the size and scale of the retail sector as evidence of urban prosperity. A link between good governance and material wealth has therefore been emphasised with paintings and frescos providing individuals with a form of visual reassurance. Paintings of fertile fields, abundant harvests and well stocked market stalls have all traditionally been used to authenticate the existing political order as well as allay fears of famine and unrest. This is illustrated in the Markets, a series of four large scale paintings commissioned by Jacques van Ophem and created by Frans Snyder (1579 - 1657) around 1618 - 1621.

As King of Spain, Philip II (1527 - 1598) ruled over seventeen separate Northern European provinces (collectively known as the Netherlands). However Philip's demand for religious uniformity and consequent persecution of the Calvinists, combined with excessive taxation demands and high levels of unemployment in the region, led to a series of revolts 
against the Spanish during the late 1560's. The Union of Utrecht in 1579 sought to unify the (mainly Protestant) Northern part of the Netherlands against Phillip II and in 1581 the Act of Abjuration saw seven Dutch provinces formally declare their independence from the Spanish Crown (Boogman 1979). The remainder of the country became known as the Spanish Netherlands and remained under the control of Hapsburg Spain. Preoccupied by a potential war with France, in 1598 Philip II ceded control of the Spanish Netherlands to his daughter Isabella and her husband, Archduke Albert of Austria. Having already come to the conclusion that it would be impossible to re-conquer the Northern Provinces, Albert sought to isolate the Dutch Republic through a number of military campaigns. The objective was to force negotiations and look to create a lasting stability in the region. Although this strategy failed to culminate in a formal peace treaty, in 1609 a twelve year truce was signed and the sovereignty of the United Provinces was recognised. Relieved of the continual drain on resources through the on-going conflict, the truce contributed to a cultural transformation that saw changes in both production and consumption. Both sides focused upon rebuilding their agricultural and commercial sectors as well as re-establishing their international trade links. Within the Spanish Netherlands, the Archduke sought to promote economic growth, encourage social and legislative reform as well as reduce anti-Spanish sentiment (Duerloo 2012).

During this period, Van Ophem occupied an influential position in the archducal government in Brussels and was a member of the emerging, upwardly mobile, 'haute bourgeoisie". By the time of the commissions he had amassed significant personal wealth from business and built a large residential property in the city. As Schroeder and Borgerson (2002) note, works of art became vehicles for expressing the materialistic aspects of home life, which in turn, led to a rapid expansion in the market for luxury goods. The Snyder paintings were hung in a part of the building where van Ophem undertook the majority of his 
business transactions and served the dual role of political propaganda as well as self promotion (Koslow 1995). The images sought to contribute to the 'atmosphere' that stimulated both cognitive and emotional responses from those who viewed the works (BiehlMissal 2012). Individuals would have recognised that the paintings celebrated the prosperity of the Spanish Netherlands and the benevolence of the Archdukes. At the same time they would have demonstrated the importance of van Ophem's own social position. As Koslow (1995) notes, commissions on the scale of the The Markets would have both signified van Ophem's role in government as well as his desire to enter into the ranks of nobility. Three of these commissioned paintings (Fish Stall, Game Stall and Fruit Stall) are examined briefly in this paper.

\section{Figure 2. The Fish Stall about here}

In contrast to Campi's portrayal of the Fishmongers, Snyder's Fish Stall (Figure 2) makes little reference to the libidinal qualities of food or the enduring social hierarchy to which retailers and other peasants classes were confined. Rather, retailing is used to signify peace and prosperity, economic stability and political order. The tables symbolise the onset of a period of growth and abundance as well as demonstrating the benevolence and prosperity of the Archduke (Koslow 1995). In addition, the Fish Stall serves to remind audiences of the benefits of the truce by highlighting its positive impact upon commerce and industry. Unemployment had fallen in the region partly due to a programme of canal building and land reclamation. In 1585 the Northern Provinces had closed the strategically important River Scheldt to shipping, a move that had restricted trade within the Spanish Netherlands. In the background of the Fish Stall, boats are moored next to the battlements of Antwerp, while in the foreground, large quantities of salt water fish are offered for sale. Snyder's work not only seeks to represent the city as a key trading port, it also reminds audiences that the offshore 
seas were once again safe and access to the waters off Zeeland and Brabant had been restored.

Similarly two other Snyder works - the Game Stall (Figure 3) and the Fruit Stall (Figure 4) illustrate the social and economic benefits of the truce. The former illustrates a butcher who is legally allowed to sell game and as Koslow (1995) observes, although the individual does not carry a horn or powder flask, the dog is a hunting hound and indicative of his profession. The inclusion of an adult swan in the centre of the picture further signifies the peace and stability brought to the country by the Archduke. According to Schneider (1990) adult swans were rarely eaten during this period as their flesh was considered too oily and unpalatable. By including the bird in the centre of the painting Snyder is seeking to further legitimise the rule of the Archdukes by emphasising the restoration of hunting for pleasure rather than for necessity.

Traditionally, the hunting of particular animals such as pheasants, stags and wild boar had been limited to those of noble birth. However the inclusion of woodcock and other small game birds in the painting was indicative of the willingness of the Archduke to grant hunting rights to non-nobles. Such imagery sought to signify the broad, encompassing nature of the truce and act as a reminder that its benefits were being enjoyed by all classes. At the same time, the painting seeks to remind audiences of the continued need to remain vigilant. The butcher's dog is fully extended on its hind legs as it attempts to chase away a cat who sits protected by a wooden screen. In iconography, cats have often been associated with the themes of treachery, trickery and wickedness (for example, being placed at the feet of Judas in paintings of the Last Supper). Snyder's depiction therefore alludes to the continued threat of the United Provinces, who despite the protection of the truce, continue to remain a constant and ever present threat. 


\section{Figure 3. The Game Stall about here}

\section{Figure 4. The Fruit Stall about here}

While Campi used a variety of foods to emphasise social division, Snyder's Fruit Stall (Figure 4) not only depicts abundance but also alludes to recovery and deliverance. New crops and harvesting methods had been introduced during the period of the truce and the overflowing tables suggests that the country was benefitting from an increase in agricultural production. A pregnant, married woman is examining a basket of (unblemished) fruit that is being offered by the seller. Bedaux (1987) identifies how fruit was used in sixteenth century paintings to symbolise fertility and attest to reproductive success and while the painting may explicitly allude to the sanctity of marriage, it may also symbolise the fecundity of the Hapsburg Netherlands and the legitimacy of Spain as a sovereign power. By including a pregnant woman in the scene, audiences would have been reminded that the Southern Netherlands was experiencing an increase in its population as individuals returned or migrated from the Dutch Republic. The woman is being offered a peach by the seller which Impelluso (2003) notes was used to represent the Holy Trinity ${ }^{2}$ and the "personification of truth". The inclusion of peaches may therefore represent the further 'saving' of the Southern Netherlands from the protestant led United Provinces and their noted intolerance of the Catholic faith. 


\section{Authenticity and the Visual}

This paper has maintained that historical contextualisation remains a fundamental prerequisite for understanding modern consumer society. Economic developments, cultural reforms as well as societal change in the fifteenth and sixteenth centuries, all represent precursors to contemporary consumption and production practices. By examining the interrelationship between production and consumption the paper has explored how product markets adapt and to respond to changing consumer values. The commodification of artistic works during the Renaissance period not only served as indicators of wealth and prestige they helped achieve the goals of image management and propaganda.

By exploring the relationship between commodification and communication, the paper proposes that product market expansion can represent a challenge to established power structures. By providing a mechanism for the expression of collective as well as individual self-interest, visual imagery afforded those outside church and state with both societal prominence as well as political and economic legitimacy. As such, the commodification of the art market during the Renaissance era provides a historical illustration of the link between consumerism and empowerment.

A central tenet of understanding the interrelationship between consumption, markets and culture remains the concept of authenticity. While the need to stimulate some form of response from the provision of verbal, visual or literary cues may be loosely linked to past events, authenticity is not dependent upon accurate depictions of history. The legitimacy of the communicated message remains reliant upon the audiences own limited knowledge of the subject matter, their capacity to make connections with the past and / or their ability to provide alternative versions of historical and current events (Arnould and Price 2000). 
Works of art are similarly not required to depict what is 'true' or 'accurate' and may actively seek to create an 'illusive reality' through a blurring of actual and fictitious events (Shepherd 2003). In this context, the paper has considered the role of visual imagery in the establishment of authenticity and the pursuit of consumer orientated needs. Through an examination of Renaissance paintings, it has argued that rather than presenting audiences with impartial reproductions of daily life, compositions often sought to reinforce specific social, political and economic agendas. In so doing, the paper has also demonstrated how authenticity remains embedded within an understanding of consumption, markets and cultures. The economic and social change that characterised the Renaissance period saw increases in wealth and power, a rise in domestic demand and a commodification of the market for artistic works. These changes combined with an evolution in artistic expression and the ascendancy of the human form, led to increases in the demand for works of art and a greater awareness of its communicative power. It has been argued that the ownership of artistic works not only sought to satisfy the needs of celebration and image management, it also a served a propagandist role designed to influence and direct public opinion (Schroeder and Borgerson 2002). The communication of meaning through visual imagery and the establishment of authenticity cannot be understood outside of this cultural context or without reference to changes within the production and consumption of art during the Renaissance era.

In addition, this paper has questioned the notion that authenticity is a reaction to modernity and reflects a growing disillusionment with consumer society (Houston and Meamber 2011; Trilling 1972). Through iconological interpretation the historical importance of artistic works in establishing authenticity has been identified. By examining the legitimising influence that visual imagery was designed to have upon Renaissance audiences, the paper further reinforces the link between art history and contemporary Western culture. 
Artistic works represent a valuable (if underutilised) data source that provide cultural meanings not revealed through other data sources. Paintings not only provide a historical context for understanding contemporary society they seek to inform our understanding of present day marketing practices (Schroeder and Borgerson 2002; Witkowski 1996)

In developing a critical approach to visual analysis Schroeder (2006) suggests that modern marketing imagery may be interpreted within the 'cultural context of consumption'. Visual media including films, adverts and photographs may be understood by reference to previous artistic traditions that serve to stimulate the aesthetic subconscious of the audience (Biehl-Missal 2012; Schroeder 2006; 2013). The ability of firms to link to a previous, bygone age has been shown to offer commercial and market related benefits. This paper suggests that the value of establishing the authentic may extend beyond economic advantage and reflect the social and / or political objectives of the organisation.

Through critical visual analysis, further research may wish to explore the authentication of socio-political meaning within marketing imagery. In so doing, it may also contribute to our understanding of how, in an era of instant communications, authenticity continues to be constructed, challenged and re-constructed. If authenticity has historically been associated with an ability to influence the process of communication, to what extent have the multiple discourses that characterise contemporary society undermined the capacity to convey and interpret meaning? Research into the consumption of modern marketing imagery will help us understand how these competing (and conflicting) pressures are balanced and maintained as well as allowing the further evolvement of authenticity to be explored. 


\section{References}

Arnould, Eric, and Linda Price. 2000. Authenticating Acts and Authoritative Performances: Questing for Self and Community. In, The Why of Consumption: Contemporary Perspectives on Consumer Motives, ed. Cynthia Huffman, Sratti Ratneswar and David Mick, 140-63. New York, Routledge.

Bedaux, Jan Baptist. 1987. Fruit and Fertility: Fruit Symbolism in Netherlandish Portraiture of the Sixteenth and Seventeenth Centuries, Simiolus: Netherlands Quarterly for the History of Art, 17, no.2/3: 150-168.

Beverland, Michael. 2005. Crafting Brand Authenticity: The Case of Luxury Wines, Journal of Management Studies 42, no.5: 1003 - 1029.

Beverland, Michael, and Francis Farrelly. 2010, The Quest for Authenticity in Consumption: Consumers' Purposive Choice of Authentic Cues to Shape Experienced Outcomes, Journal of Consumer Research, 36, no.5: 838 - 856.

Beverland, Michael, Adam Lindgreen, and Michiel Vink. 2008, Projecting Authenticity through Advertising: Consumer Judgments of Advertisers' Claims, Journal of Advertising, 37, no. $1: 5-15$.

Biehl-Missal, Brigitte. 2013. The atmosphere of the image: an aesthetic concept for visual analysis, Consumption Markets \& Culture, 16, no.4: 356-367.

Boogman, Johan. 1979. The Union of Utrecht: its Genesis and Consequences, BMGN - Low Countries Historical Review, 94, no. 3: 377 - 407.

Brown, Christopher. 1999. Scenes of Everyday Life: Dutch Genre Paintings from the Mauritshuis, Oxford, Ashmolean.

Brown, Stephen, Robert Kozinets, and John Sherry. 2003. Teaching Old Brands New Tricks: Retro Branding and the Revival of Brand Meaning, Journal of Marketing, 67:19 -33.

Chronis, Athinodoros, Eric Arnould, and Ronald Hampton. 2012. Gettysburg re-imagined: the role of narrative imagination in consumption experience, Consumption Markets \& Culture, 15, no 3: 261-286.

Cohen, Erik. 1988. Authenticity and Commoditization in Tourism, Annals of Tourism Research, 15, no.3: 371-386.

Derbaix, Maud, and Alain Decrop. 2007. Authenticity in the Performing Arts: A Foolish Quest? ,Advances in Consumer Research 34: 75-80.

Duerloo, Luc. 2012. Dynasty and Piety: Archduke Albert (1598-1621) and Habsburg Political Culture in an Age of Religious Wars. Surrey: Ashgate Publishing.

Edelman, Murray. 1995. From Art to Politics: how artistic creations shape political conceptions, Chicago, Chicago University Press. 
Edwards, Lee. 2010. Authenticity in organisational context: fragmentation, contradiction and loss of control, Journal of Communication Management 14, no.3: 192-205.

Falkenburg, Reindert. 1995. Pieter Aertsen, Rhyparographer. In Rhetoric-RhétoriquersRederijkers, ed. Jelle Koopmans, Mark Meadow, and Marijke Spies, 197-215. Amsterdam: Royal Netherlandish Academy of Arts and Sciences.

Falkenburg, Reindert. 1996. Matters of Taste: Pieter Aertsen's Market Scenes, Eating Habits, and Pictorial Rhetoric in the Sixteenth Century. In The Object as Subject. Studies in the Interpretation of Still Life, ed. Anne Lowenthal, pp.13 - 27. Princeton, NJ: Princeton University Press.

Fine, Gary. 2006. Everyday Genius: Self-Taught Art and the Culture of Authenticity, Chicago, University of Chicago Press.

Firat, Fuat, and Ebru Ulusoy. 2011. Living a theme, Consumption Markets \& Culture, 14, no. 2: 193-202.

Gombrich, Ernst. 1985. Gombrich on the Renaissance, Volume 2: Symbolic Images, London, Phaidon.

Grayson, Kent, and Radan Martinec. 2004. Consumer perceptions of Iconicity and Indexicality and their influence on assessments of authentic market offerings, Journal of Consumer Research, 31, no.2: 296-312.

Häberlein, Mark. 2012. The Fuggers of Augsburg: Pursuing Wealth and Honor in Renaissance Germany, Virginia, University of Virginia Press.

Hall, Marie. 1994. The Scientific Renaissance 1450-1630, Ontario, General Publishing.

Harrison, Paul. 2009. Evaluating artistic work: Balancing competing perspectives, Consumption Markets \& Culture, 12, no. 3: 265-274.

Hartmann, Benjamin, and Jacob Ostberg. 2012. Authenticating by re-enchantment: The discursive making of craft production, Journal of Marketing Management, 29, no.7-8: 882-911.

Hede, Anne-Marie, and Maree Thyne. 2010, A journey to the authentic: Museum visitors and their negotiation of the inauthentic, Journal of Marketing Management 26, no 7-8: 686-705.

Higson, Andrew. 2014. Nostalgia is not what it used to be: heritage films, nostalgia websites and contemporary consumers, Consumption Markets \& Culture, 17, no. 2: 120-142.

Hirsch, Eric. 1967. Validity in Interpretation. New Haven: Yale University Press.

Holbrook, Morris. 1989. Seven routes to facilitating the Semiological Interpretation of Consumption Symbolism and Marketing Imagery in works of art: Some tips for wildcats, Advances in Consumer Research 16: 420-425.

Holt, Douglas. 2004. How Brands Become Icons: The Principles of Cultural Branding. Cambridge, MA: Harvard Business School Press. 
Houston, Rika, and Laurie Meamber. 2011. Consuming the "world": reflexivity, aesthetics, and authenticity at Disney World's EPCOT Center, Consumption Markets \& Culture, 14, no. 2: $177-191$.

Impelluso, Lucia. 2003. Nature and its Symbols. Los Angeles: Getty Publications.

Jardine, Lisa. 1996. Worldly Goods: A New History of the Renaissance. London: Norton and Company.

Koslow, Susan. 1995. Frans Snyders: The Noble Estate. Seventeenth-Century Still-Life and Animal Painting in the Southern Netherlands, Antwerp: Fonds Mercator.

Maruyama, Naho, Tsu Hong Yen, and Amanda Stronza. 2008. Perception of Authenticity of Tourist Art among Native American Artists in Santa Fe, New Mexico, International. Journal of Tourism Research 10: 453-466.

MacCannell, Dean. 1973. Staged Authenticity: Arrangements of Social Space in Tourist Settings, American Journal of Sociology, 79, no.3: 589-603.

MacCannell, Dean. 1976, The Tourist: A New Theory of the Leisure Class, Berkeley, University of California Press.

McKiernan, Mike. 2008. Images of work. Occupational Medicine, 58, no.3:156-158.

McTighe, Sheila. 2004. Foods and the Body in Italian Genre Paintings, about 1580: Campi, Passarotti, Carracci. The Art Bulletin, 86, no.2: 301-323.

Miller, Maureen. 2000. Religion Makes a Difference: Clerical and Lay Cultures in the Courts of Northern Italy, 1000-1300. The American Historical Review, 105, no.4: 1095-1130 .

Newman, George. and Paul Bloom. 2012., Art and Authenticity: The Importance of Originals in Judgments of Value, Journal of Experimental Psychology 141, no.3: 558-569.

Osborne, Brian. 1998. Constructing landscapes of power: the George Etienne Cartier monument, Montreal, Journal of Historical Geography, 24, no.4: 431-458.

Panofsky, Erwin. 1970. Meaning in the visual arts. Harmondsworth : Penguin. Originally published, New York: Doubleday, 1955.

Panofsky, Erwin. 1971. Studies in iconology: humanistic themes in the art of the Renaissance. London: Harper and Row.

Peñaloza, Lisa. 2001. Consuming the American West: Animating Cultural Meaning and Memory at a Stock Show and Rodeo, Journal of Consumer Research 28, no.3: 369 - 398.

Peterson, Richard. 1997. Creating country music: Fabricating authenticity. Chicago: University of Chicago Press. 
Potter, Andrew. 2010. The authenticity hoax: How we get lost finding ourselves. New York: HarperCollins Publishers.

Pracejus, John, Thomas O'Guinn, and Douglas Olsen. 2013. When white space is more than "burning money": Economic signalling meets visual commercial rhetoric, International Journal of Research in Marketing, 30, no. 3: 211 - 218.

Rose, Randall, and Stacey Wood. 2005. Paradox and the Consumption of Authenticity through Reality Television, Journal of Consumer Research, 32, no.2: 284-296.

Schneider, Norbert. 1990. The Art of the Still Life, Berlin, Taschen.

Schroeder, Jonathan. 1999. Consuming Representation: Insights From Dutch Art of the Golden Age, Advances in Consumer Research, 26: 641-643.

Schroeder, Jonathan. 2005. The artist and the brand, European Journal of Marketing, 39, no.11/12: 1291-1305.

Schroeder, Jonathan. 2006. Critical Visual Analysis. In Handbook of Qualitative Research Methods in Marketing, ed. Russell Belk, 303 - 321. Gloucester, Elgar Publishing.

Schroeder, Jonathan. 2013. Snapshot Aesthetics and the Strategic Imagination, Invisible Culture, 18. Available at http://ivc.lib.rochester.edu/portfolio/snapshot-aesthetics-and-thestrategic-imagination/ last accessed 31 January 2014.

Schroeder, Jonathan and Borgerson, Janet. 2002. Innovations in Information Technology: Insights from Italian Renaissance Art, Consumption Markets \& Culture 5, no.2: 153-169.

Shepherd, Robert. 2003. Fieldwork without remorse: Travel desires in a tourist world, Consumption Markets \& Culture, 6, no.2: 133-144.

Soppelsa, Robert. 1988. Western Art-Historical Methodology and African Art: Panofsky's Paradigm and Ivoirian Mma, Art Journal, 47, no.2: 147-153.

Stern, Barbara, and Jonathan Schroeder. 1994, 'Interpretive methodology from Art and Literary Criticism: a humanistic approach to advertising imagery', European Journal of Marketing. 28, no.3: 114-132.

Sullivan, Margaret. 1999. Aertsen's Kitchen and Market Scenes: Audience and Innovation in Northern Art, The Art Bulletin, 81, no.2: 236-266.

Torikian, Garen. 2010. Against a Perpetuating Fiction: Disentangling Art from Hyperreality, The Journal of Aesthetic Education, 44, no.2: 100-110.

Trilling, Lionel. 1972. Sincerity and Authenticity, Harvard, Harvard University Press.

Wang, Ning. 1999. Rethinking Authenticity in Tourism Experience, Annals of Tourism Research, 26, no.2: 349-370.

Welch, Evelyn. 2005. Shopping in the Renaissance, New Haven, Yale. 
Witkowski, Terence. 1996. Farmers Bargaining: Buying and Selling as a Subject in American Genre Painting 1835 - 1869, Journal of Macromarketing, 17, Fall: 84-101.

Wind, Barry. 1974. Pitture ridicule: Some late Cinquecento Comic Genre Paintings, Storia dell'Arte 20, pp.24 - 35.

Zayer, Linda, Katherine Sredl, Marie-Agnès Parmentier, and Catherine Coleman. 2012.

Consumption and gender identity in popular media: discourses of domesticity, authenticity, and sexuality, Consumption Markets \& Culture, 15, no. 4: 333-357. 
Figure 1 The Fishmongers (c1580)

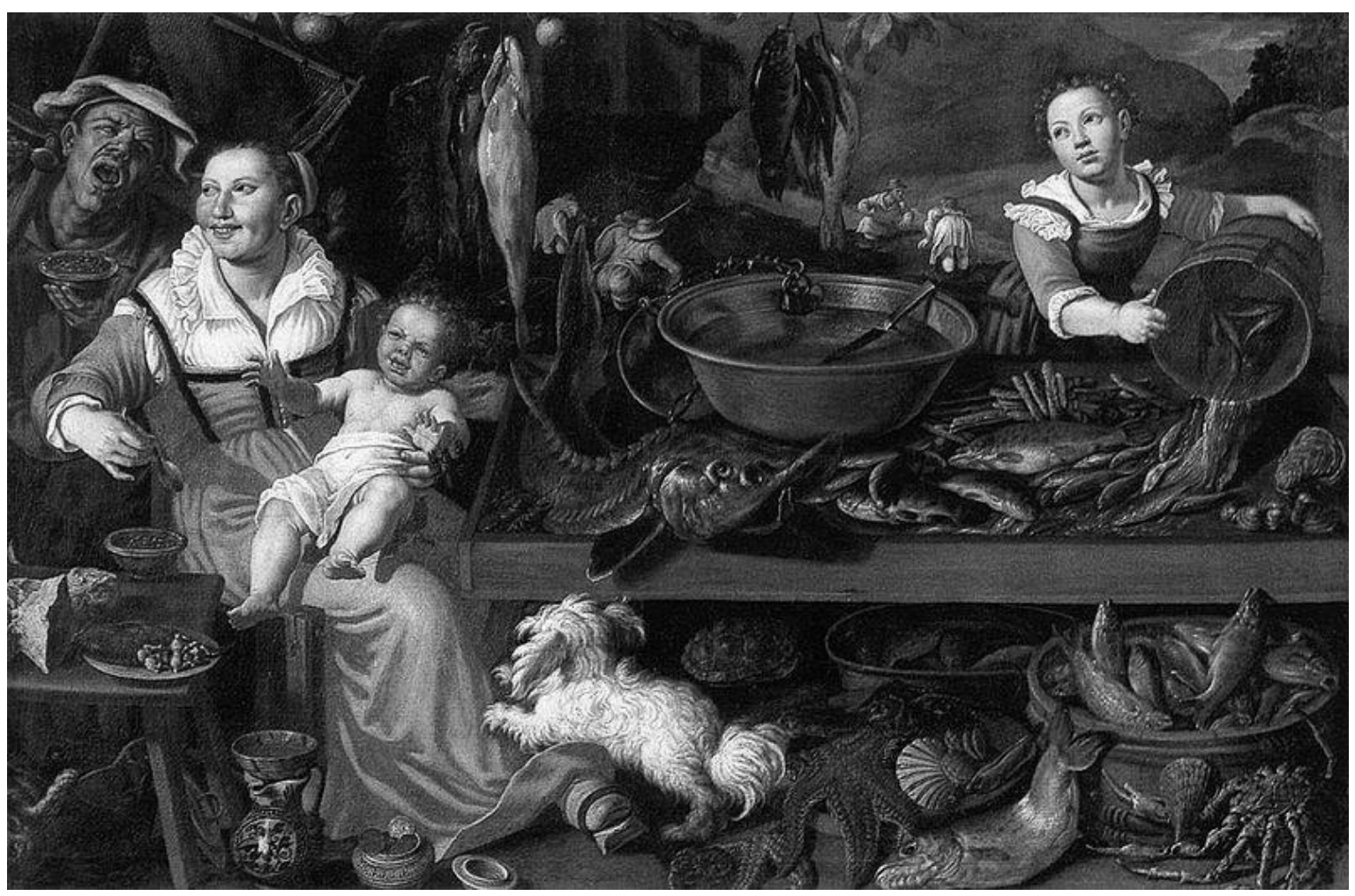


Figure 2. The Fish Stall (c.1620)

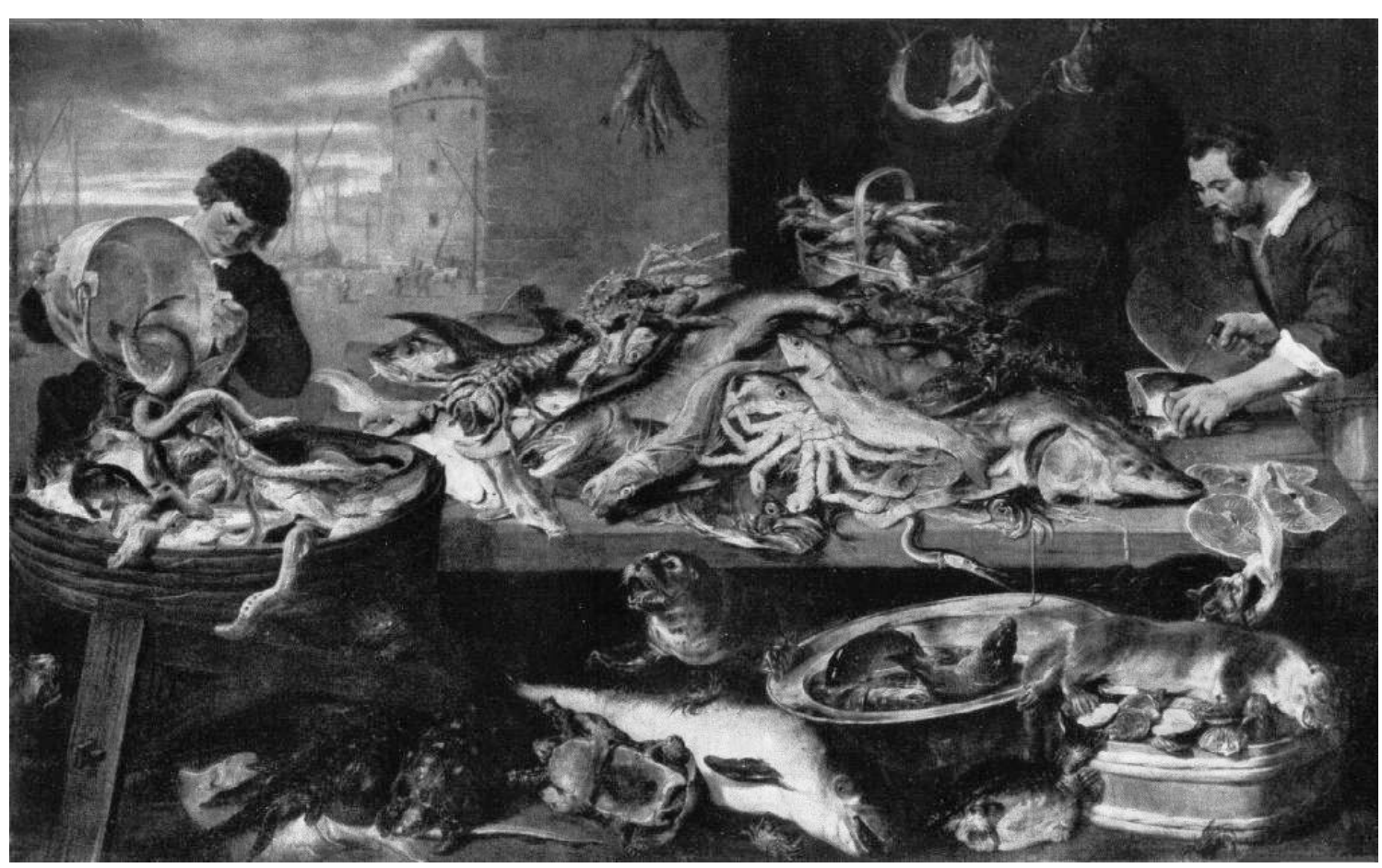


Figure 3. The Game Stall (c.1620)

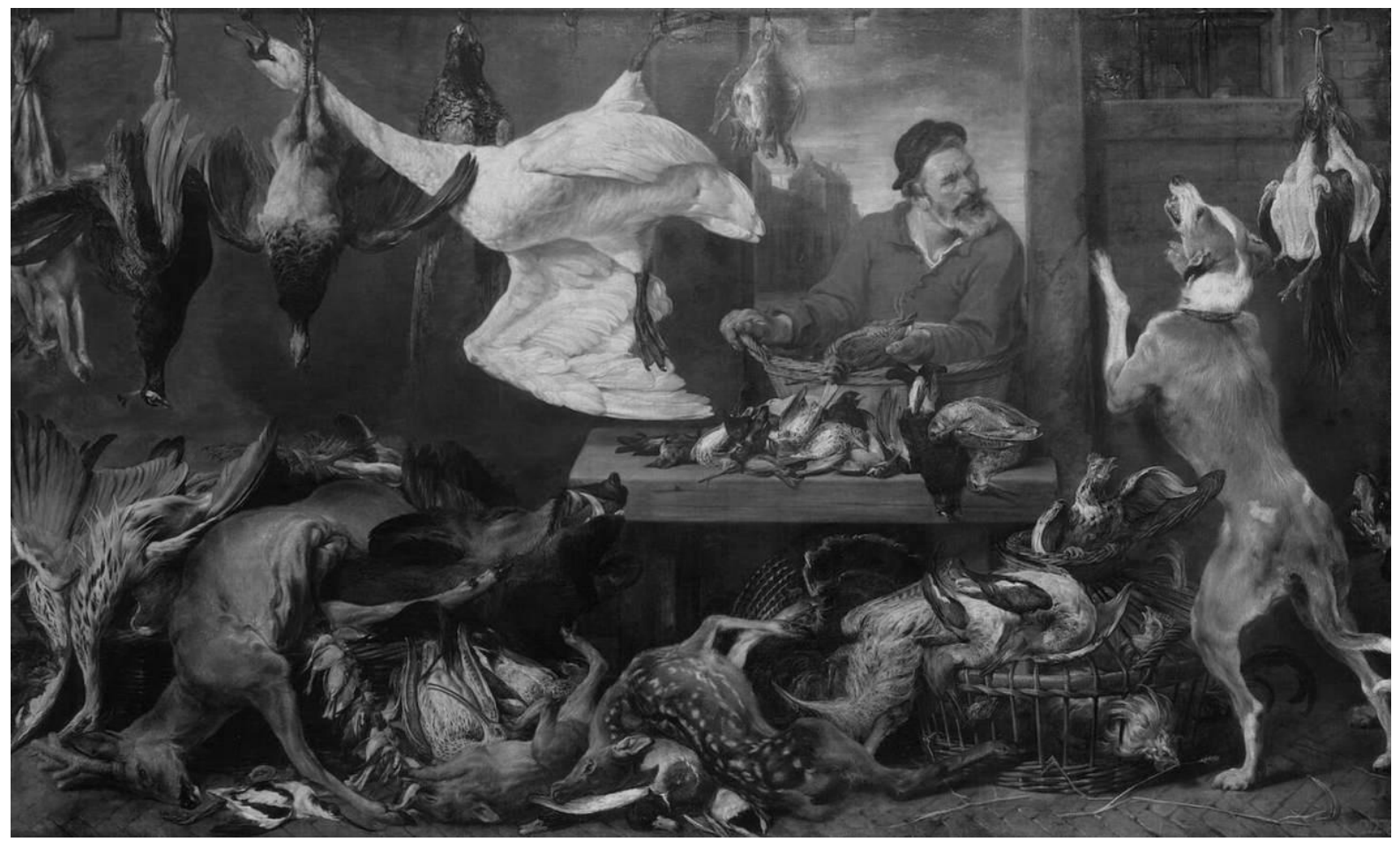


Figure 4. The Fruit Stall (c.1620)

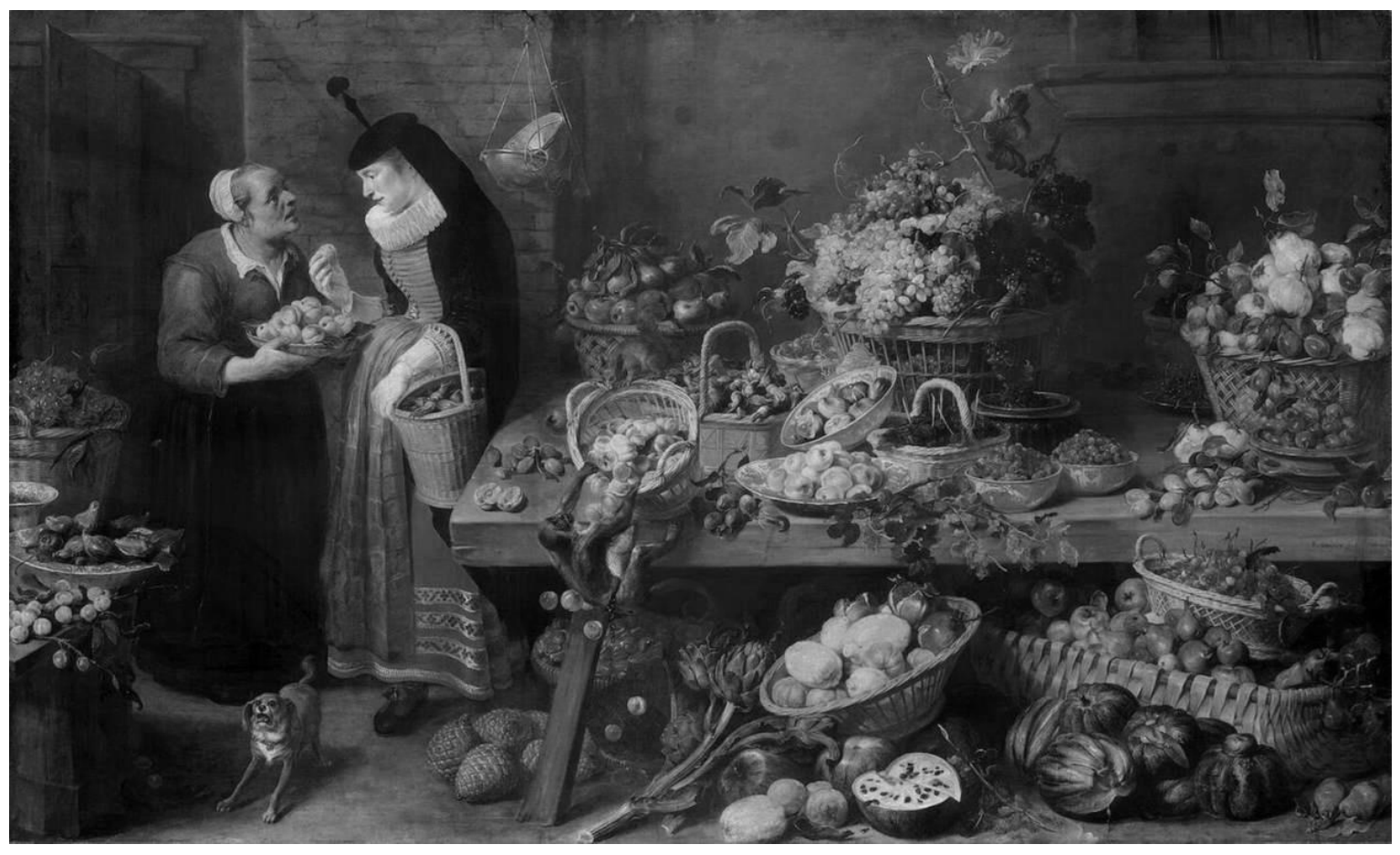




\begin{abstract}
${ }^{1}$ The inclusion of noble foods is a recurring theme within many genre compositions. Falkenburg (1996) for example notes how in addition to everyday fruit and vegetables, rich families in the Netherlands were able to avail themselves to 'noble fruits' such as almonds, olives, figs and oranges imported from Spain and Portugal. ${ }^{2}$ Peaches were considered as having three separate parts, the fruit itself, the pit and the seed inside the pit each representing one part of the Holy Trinity.
\end{abstract}

